evidence of the explanted valves, they concluded that 2 of the bioprostheses were thrombosed and that the other 2 had coagulated blood on the outflow of the cusps and thus should not be classified as demonstrating structural valve dysfunction. This view was not shared by Flameng and associates, ${ }^{4}$ however, who hypothesized that early stenotictype valvular dysfunction in the 4 reported cases was perhaps related to patient-prosthesis mismatch or turbulent transvalvular flow. Their definition of moderate patientprosthesis mismatch for patients with an indexed EOA of less than 0.85 has since been challenged by Jamieson and colleagues. ${ }^{5}$

We have presented the cases of 2 patients with early stenotic valve failure who did not have any evidence of patient-prosthesis mismatch, and had postoperative indexed EOAs of $0.90 \mathrm{~cm}^{2} / \mathrm{m}^{2}$ and $0.83 \mathrm{~cm}^{2} / \mathrm{m}^{2}$. In addition, the explanted valves did not reveal any pannus formation or histologic evidence of thrombosis, although thrombosis could not be ruled out in the first case on the basis of the available evidence. Importantly, there was no evidence of subtherapeutic anticoagulation or procoagulant states, and our patients had normal renal function, without any documented hypercalcemic syndromes. After detailed pathologic examination, it remains unclear what caused the early valvular dysfunction of the Mosaic bioprostheses in our patients. In view of our findings, however, we believe that there is a need for clinical vigilance with regular echocardiographic follow-up in patients who have had implantation of Mosaic aortic bioprosthetic valves.

\section{References}

1. Fradet GJ, Bleese N, Burgess J, Cartier PC. Mosaic valve international clinical trial: early performance results. Ann Thorac Surg. 2001;71(5 Suppl):S273-7.

2. Lawton JS, Moazami N, Pasque MK, Moon MR, Damiano RJ Jr. Early stenosis of Medtronic Mosaic porcine valves in the aortic position. J Thorac Cardiovasc Surg. 2009;137:1556-7.

3. Jamieson WR, Fradet GJ. Aortic bioprosthesis - avoid obstructive properties due to thrombosis as altered durability due to structural valve deterioration. J Thorac Cardiovasc Surg. 2010;139:1354.

4. Meuris B, Flameng W. Relation between hemodynamic behavior and occurrence of early stenotic failure of bioprostheses. J Thorac Cardiovasc Surg. 2010;140: 1200 .

5. Jamieson WR, Fradet GJ. Relation between hemodynamic behavior and occurrence of early stenotic failure of bioprostheses: reply to the editor. J Thorac Cardiovasc Surg. 2010;140:1200-1.

\title{
Saphenous vein graft bronchopulmonary fistula after coronary artery bypass grafting presenting as chronic cough and subsequent massive hemoptysis
}

\author{
Elizabeth Belcher, MRCP, FRCS, PhD, ${ }^{\mathrm{a}}$ Edward Townsend, FRCS, ${ }^{\mathrm{a}}$ and Fabio De Robertis, MD, ${ }^{\mathrm{b}}$ London, \\ United Kingdom
}

Aortocoronary conduit bronchopulmonary fistula is a rare, potentially lethal complication seen after coronary artery bypass grafting $(\mathrm{CABG})$. The ideal diagnostic modality in such cases is not established. We present a case of earlyonset aortocoronary conduit bronchopulmonary fistula diagnosed by coronary angiography and immediate noncontrast computed tomography $(\mathrm{CT})$ in a patient with massive hemoptysis 8 weeks after CABG.

\footnotetext{
From the Departments of Thoracic Surgery ${ }^{\mathrm{a}}$ and Cardiac Surgery, ${ }^{\mathrm{b}}$ Harefield Hospital, London, United Kingdom.

Disclosures: Authors have nothing to disclose with regard to commercial support.

Received for publication Sept 4, 2011; revisions received Sept 24, 2011; accepted for publication Oct 20, 2011; available ahead of print Nov 21, 2011.

Address for reprints: Fabio De Robertis, MD, Department of Cardiac Surgery, Harefield Hospital, Hill End Rd, Harefield, Middlesex, UB9 6JH, UK (E-mail: f.derobertis@ rbht.nhs.uk).

J Thorac Cardiovasc Surg 2012;143:e14-6

$0022-5223 / \$ 36.00$

Copyright (C) 2012 by The American Association for Thoracic Surgery doi:10.1016/j.jtcvs.2011.10.042
}

\section{CLINICAL SUMMARY}

A 75-year-old woman underwent elective CABG. Conduits were fashioned from left internal thoracic artery to left anterior descending coronary artery and long saphenous vein graft to posterior descending coronary artery. The ascending aorta was noted to be thin walled and dilated, measuring $3.6 \mathrm{~cm}$. On removal of the cardioplegia cannula from the ascending aorta, a complex $2-\mathrm{cm}^{2}$ tear was noted. Control of this area was undertaken by fashioning the proximal aorta-saphenous vein graft anastomosis in an oversized manner.

At follow-up, the patient was noted to have acquired a chronic cough. At 8 postoperative weeks, the patient had sudden significant hemoptysis. Contrast chest CT demonstrated a filling defect in the bronchus intermedius, consistent with hemorrhage, retrosternal fluid collection, and opacification within the medial portion of the right upper lobe (Figure 1, A). Rigid bronchoscopy showed large amounts of blood throughout the tracheobronchial tree but no active bleeding point. Coronary angiography 

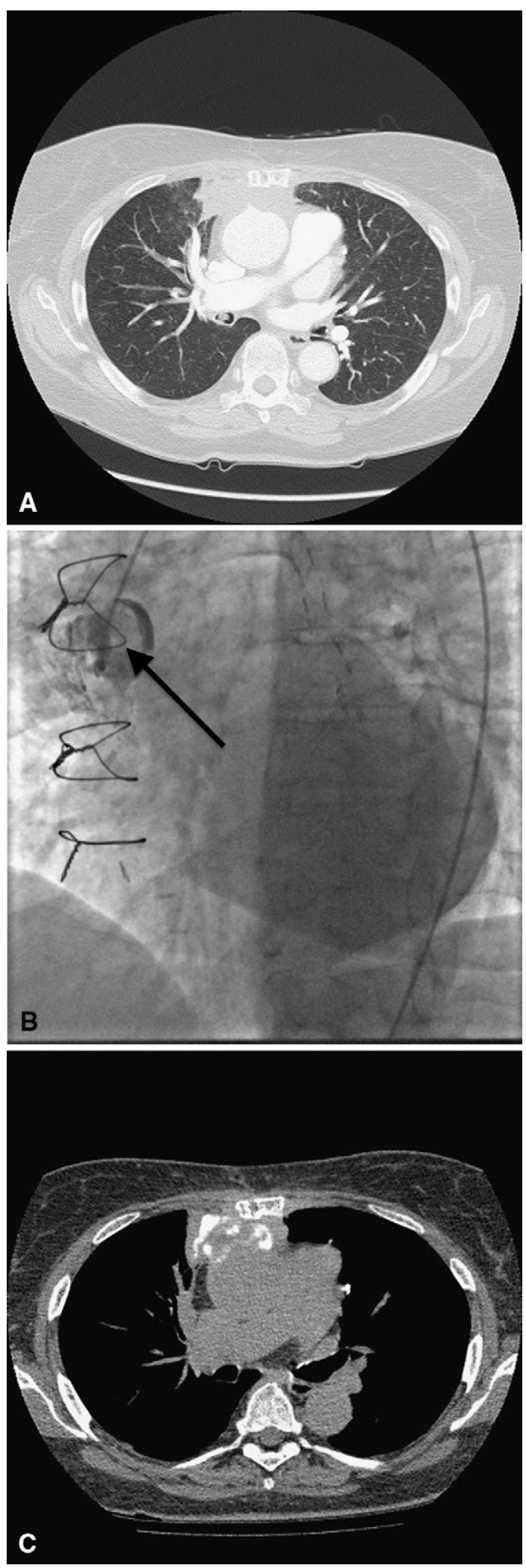

FIGURE 1. A, Contrast chest computed tomography demonstrating filling defect in the bronchus intermedius consistent with hemorrhage within airway, retrosternal fluid collection, and opacification of the right upper demonstrated a patent left internal thoracic artery graft to the left anterior descending coronary artery and absence of flow within the saphenous vein graft (Figure 1, B). Injection of contrast within the saphenous vein graft was associated with further significant hemoptysis. Noncontrast CT chest performed immediately after coronary angiography demonstrated extravasation of contrast from the saphenous vein graft lying retrosternally and within the right upper lobe, consistent with aortocoronary conduit fistula (Figure 1,C). At resternotomy, a large retrosternal paraaortic collection was noted at the site of the previous vein graft (Figure 2, A), and a fistulous tract was demonstrated between this area and the right upper lobe (Figure 2, B). The fistula and the vein graft were isolated and transected, and the aorta was repaired with bovine pericardium. The patient had a full recovery after a protracted intensive care stay for respiratory failure.

\section{DISCUSSION}

Aortocoronary conduit bronchopulmonary fistula is a rare but potentially lethal complication of CABG; however, the optimal diagnostic modality is unknown. We present a case of saphenous vein graft pulmonary fistula diagnosed by coronary angiography and immediate noncontrast chest CT in a patient with chronic cough and massive hemoptysis 8 weeks after CABG. Fistulous connections have been reported in association with both internal thoracic artery and saphenous vein grafts. Conduits may fistulate into the cardiac chambers, ${ }^{1}$ pulmonary vasculature, ${ }^{2}$ or the lung parenchyma. ${ }^{3}$ The most common presentation of aortocoronary conduit bronchopulmonary fistula is recurrent angina resulting from steal phenomenon; however, other reported modes of presentation include myocardial infarction resulting from distal embolization and congestive cardiac failure. ${ }^{4}$

Fistulas are usually although not exclusively associated with aneurysmal dilation of the graft and most commonly are seen 10 to 20 years after $\mathrm{CABG}^{1}$ and in association with atretic grafts. In our case, symptomatic saphenous bronchopulmonary fistula was diagnosed only 8 weeks after CABG. This is to our knowledge the earliest presentation of such a fistula after CABG. Benchimol and colleagues ${ }^{5}$ proposed mechanisms of aneurysm formation inferred from the tendency of these legions to occur in certain regions of the venous graft, including in the vicinity of

lobe. B, Coronary angiography. Arrow demonstrates absence of flow within the saphenous vein graft to the right coronary artery. C, Noncontrast chest computed tomography performed immediately after coronary angiography demonstrating extravasation of contrast from the saphenous vein graft lying retrosternally and within the right upper lobe consistent with aortocoronary conduit fistula. 

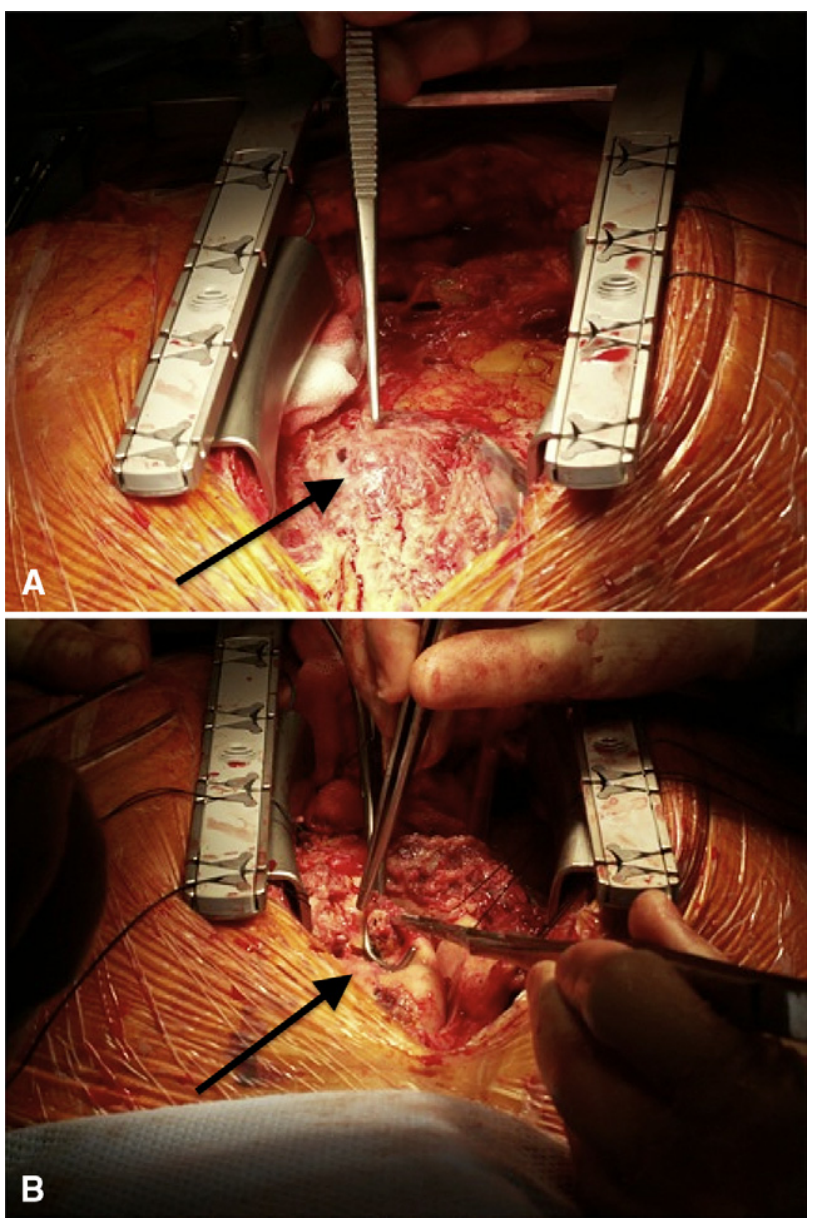

FIGURE 2. A, Intraoperative photograph. Arrow demonstrates retrosternal para-aortic collection at site of right coronary vein graft. B, Intraoperative photograph. Arrow shows fistula between saphenous vein graft (transected) and right lung.

valves because of the lack of circular muscle in these areas, at branch sites, in areas of iatrogenic injury, and at sites of atherosclerotic degeneration and vein wall necrosis or infection. In our case, it is likely that the etiology of fistula formation was related to the fashioning of an oversized proximal anastomosis to deal with the aortic tear caused by the cardioplegia cannula, possibly in association with vein wall necrosis and infection as a result of application of surgical sealant.

Although in some cases fistulas may be asymptomatic, indications for treatment include refractory angina, heart failure, endocarditis, or, as in this case, hemoptysis. Surgical resection is the standard treatment; however, percutaneous coil embolization and covered stent deployment have also been successfully used. ${ }^{1}$ Suggested diagnostic modalities include echocardiography, CT, magnetic resonance imaging, and angiography. Although bronchial angiography may be useful in cases of hemoptysis, it is limited to specialist centers, is technically challenging, and requires the patient to be actively bleeding at the time of angiography. In our case, we performed coronary angiography, which was not clearly diagnostic of a fistula. Angiography precipitated a further episode of hemoptysis, and subsequent noncontrast chest CT clearly showed contrast injected at coronary angiography present within the anterior mediastinum and airway of the right lung. We suggest that when aortocoronary graft fistula is suspected, the diagnostic algorithm of choice is coronary angiography immediately followed by noncontrast CT.

\section{References}

1. Le Breton H, Pavin D, Langanay T, Roland Y, Leclercq C, Beliard JM, et al. Aneurysms and pseudoaneurysms of saphenous vein coronary artery bypass grafts. Heart. 1998;79:505-8.

2. Pase-Sosland R, Gadallah S, Gupta K. Association of atretic left internal mammary graft with internal mammary to pulmonary vasculature fistula: a case series. J Invasive Cardiol. 2010;22:E185-8.

3. Gypen BJ, Poniewierski J, Rouhanimanesh Y, Dieudonné T, Van Mulders AP, d'Archambeau OC, et al. Severe hemoptysis 6 years after coronary artery bypass grafting. Ann Thorac Surg. 2003;75:999-1001.

4. Guray U, Guray Y, Ozbakir C, Yilmaz MB, Sasmaz H, Korkmaz S. Fistulous connection between internal mammary graft and pulmonary vasculature after coronary artery bypass grafting: a rare cause of continuous murmur. Int $J$ Cardiol. 2004;96:489-92.

5. Benchimol A, Harris CL, Desser KB, Fleming H. Aneurysms of an aortocoronary artery saphenous vein bypass graft-a case report. Vasc Surg. 1975; 9:261-4. 